\title{
ANALISIS POTENSI DEMAND BATIK SOLO TRANS KORIDOR 2 PADA FUNGSI GUNA LAHAN PERTOKOAN DAN ANALISIS ABILITY TO PAY(ATP) DAN WILLINGNESS TO PAY (WTP)
}

\author{
Bagus Saputra $\mathbf{P}^{1)}$, Slamet Jauhari Legowo ${ }^{2)}$, Budi Yulianto ${ }^{3)}$ \\ 1) Mahasiswa Program S1 Teknik Sipil, Universitas Sebelas Maret \\ ${ }^{23)}$ Pengajar Program Studi Teknik Sipil, Universitas Sebelas Maret \\ Jalan Ir. Sutami No. 36 A Surakarta 57126. Telp: (0271) 647069. Email: baguspramsun@ gmail.com
}

\begin{abstract}
The need for transportation at this time continues to increase and this results in congestion if not handled properly. One ideal way is to provide mass public transportation such as Batik Solo Trans (BST). The addition of demand is an important factor in the development of mass public transport. In addition, the determination of tariffs must also consider ability and willingness of demand for them interested and willing to switch to public transportation. The purpose of this study is to determine the potential demand and analysis of ATP and WTP from the potential demand on the BST corridor 2 of land use stores. The research data is obtained by distributing questionnaires to employees and visitors who are on the function of land use stores. Then the data is analyzed to know the magnitude of potential demand and to know the value of ATP and WTP to pay BST tariff.The result of data analysis shows the potential demand of BST corridor 2 on the function of land use stores is 10.714 people, that is 59,65\% from total 17,961 population. The value of ATP and WTP is divided into three categories, namely general, employees and visitors. ATP value of general category is $\mathrm{R} p 2,287,59$, ATP employee category value is $\mathrm{Rp} 2,157.50$, and ATP value of visitor category is $\mathrm{R} p 2,509,24$. While the value of the $\mathrm{P} A P$ for the general category of $\mathrm{R} p 4,035.27$, the value of $\mathrm{P} A P$ employee category of $\mathrm{R} p$ 3,966.67, and the value of WTP category visitors amounting to Rp 4.131,87. The condition shows the ATP value is lower than the value of WTP and still below the current rate of $\mathrm{R} p 4,500.00$.
\end{abstract}

Key word: Potential demand, Ability to Pay (ATP), Willingness to Pay (WTP), BST

Abstrak

Kebutuhan akan transportasi pada saat ini terus meningkat dan hal ini mengakibatkan kemacetan jika tidak ditangani denga baik. Salah satu cara yang ideal adalah dengan menyediakan angkutan umum massal seperti Batik Solo Trans (BST). Penambahan demand merupakan faktor penting dalam pengembangan angkutan umum massal tersebut. Selain itu, penentuan tarif juga harus memperhitungkan kemampuan dan kesediaan dari demand agar mereka tertarik dan mau beralih pada angkutan umum. Tujuan dari penelitian ini adalah untuk mengetahui potensi demand serta analisis ATP dan WTP dari potensi demand tersebut pada rute BST koridor 2 pada fungsi guna lahan pertokoan. Data penelitian diperoleh dengan penyebaran kuisioner kepada pegawai dan pengunjung yang berada pada fungsi guna lahan pertokoan. Kemudian data dianalisis untuk mengetahui besarnya potensi demand dan mengetahui nilai ATP dan WTP untuk membayar tarif BST. Hasil analisis data menunjukkan potensi demand BST koridor 2 pada fungsi guna lahan pertokoan adalah 10.714 orang, yaitu 59,65\% dari total 17.961 populasi. Nilai ATP dan WTP dibagi menjadi tiga kategori,yaitu umum, pegawai dan pengunjung. Nilai ATP kategori umum sebesar Rp 2.287,59, nilai ATP kategori pegawai sebesar Rp 2.157,50, dan nilai ATP kategori pengunjung sebesar Rp 2.509,24. Sedangkan nilai WTP untuk kategori umum sebesar Rp 4.035,27, nilai WTP kategori pegawai sebesar Rp 3.966,67, dan nilai WTP kategori pengunjung sebesar Rp 4.131,87. Kondisi tersebut menunjukan nilai ATP lebih rendah daripada nilai WTP dan masih di bawah nilai tariff yang berlaku saat ini yaitu sebesar Rp 4.500,00.

Kata kunci : Potensi demand, Ability to Pay (ATP), Willingness to Pay (WTP), BST

\section{PENDAHULUAN}

Perkembangan transportasi dalam negeri terus meningkat seiring berjalannya waktu. Kepemilikan kendaraan pribadi menjadi solusi untuk menunjang pergerakan bagi sebagian besar orang. Kondisi tersebut menjadi potensi timbulnya kemacetan jika tidak diiringi dengan peningkatan kapasitas jalan. Menurut Sinulingga (1999) pencapaian kondisi yang ideal dalam sistem transportasi sangat ditentukan oleh berbagai faktor, antara lain 
kondisi prasarana (jalan), sistem jaringan jalan, kondisi sarana (kendaraan) dan sikap mental pemakai fasilitas transportasi tersebut.

Surakarta merupakan kota yang sedang mengalami perkembangan yang cukup pesat di berbagai bidang seperti ekonomi dan pariwisata. Perkembangan tersebut tidak lepas dari adanya dukungan sektor transportasi. Bentuk dukungan tersebut adalah berupa moda transportasi angkutan umum. Ada berbagai macam angkutan umum yang telah disediakan di Surakarta yang salah satunya adalah Batik Solo Trans (BST).

Dalam penelitiannya, Albertus Ryan (2014) menyebutkan bahwa nilai load factor eksisting dari BST koridor 2 pada hari kerja sebesar 52,25\% dan pada hari libur sebesar 40,93\%, sedangkan target dari perencanaan awal adalah sebesar 70\%. Hal ini akan membebani operator, yakni PT. Bengawan Solo Transport dalam pengoperasionalannya. Salah satu solusi agar operasional BST tetap berjalan yaitu dengan meningkatkan nilai load factor agar sesuai dengan perencanaan. Peningkatan tersebut dapat dilakukan dengan melihat area sekitar BST koridor 2 sebagai area dari demand yang potensial. Area tersebut dibagi menjadi empat fungsi guna lahan, yaitu : Perumahan, Perkantoran, Pendidikan, dan Pertokoan. Fungsi guna lahan pertokoan dapat menjadi potensi karena cukup banyak pertokoan yang berada di sepanjang koridor 2 BST sehingga pegawai dan pengunjung berpotensi untuk menggunakan angkutan umum. Ketidak mampuan memiliki kendaraan pribadi, biaya dan jarak perjalanan menjadi faktor pertimbangan pegawai dan pengunjunug beralih menggunakan angkutan umum BST.

Ada beberapa metode dalam menentukan tarif angkutan umum. Mengetahui nilai Ability to Pay (ATP) dan Willingness to Pay (WTP) merupakan salah satu metode dalam menentukan tarif angkutan umum. Apabila daya beli masyarakat dan kemamuan masyarakat untuk membayar angkutan umum lebih kecil daripada tarif yang berlaku maka pengguna relative lebih memilih berganti menggunakan kendaraan pribadi.

\section{DASAR TEORI}

\section{Analisis Potensi Demand}

Analisis potensi demand merupakan analisis untuk mengetahui jumlah calon penumpang BST yang bisa beralih dari kendaraan pribadi ke BST (Reza Alfiano, 2015). Analisis potensi demand diperlukan untuk mengetahui penambahan penumpang dari daerah dengan guna lahan pertokoan yang bisa dikembangkan oleh BST koridor 2 .

\section{Pertokoan}

Pertokoan berasal dari kata toko yang berarti bangunan permanen tempat menjual barang-barang, sedangkan pertokoan adalah tempat atau kompleks toko (Kamus Besar Bahasa Indonesia, 2016). Secara fungsi ekonomi, istilah toko sesungguhnya hampir sama dengan kedai atau warung. Akan tetapi pada perkembangan istilah, kedai dan warung cenderung bersifat tradisional dan sederhana, dan warung umumnya dikaitkan dengan tempat penjualan makanan dan minuman. Secara bangunan fisik,toko lebih terkesan mewah dan modern dalam arsitektur bangunannya daripada warung

\section{Ability To Pay}

Ability To Pay (ATP) adalah kemampuan seseorang untuk membayar jasa pelayanan yang diterimanya berdasarkan penghasilan yang dianggap ideal. Rumus yang digunakan dalam mencari nilai ATP adalah :

$$
\begin{aligned}
& A T P=\frac{I C . \% T C}{D} \\
& \text { Di mana : } \\
& \text { Ic }=\text { Penghasilan } \\
& \% \mathrm{TC}=\text { Persentase dari penghasilan untuk travel cost } \\
& \mathrm{D} \quad=\text { Frekuensi perjalanan }
\end{aligned}
$$

\section{Willingness To Pay}

Willingness To Pay (WTP) adalah kesediaan pengguna mengeluarkan imbalan atas jasa yang telah diterimanya. . Pendekatan yang digunakan dalam analisis WTP didasarkan atas persepsi pengguna terhadap tarif dan jasa pelayanan angkutan umum tersebut. Rumus yang digunakan dalam mencari nilai WTP adalah :

$M W T P=\frac{1}{n} \sum_{i=1} n W T P i$

Di mana :

MWTP = Rata-rata WTP 
$\begin{array}{ll}\mathrm{n} & =\text { Ukuran sampel } \\ \text { WTPi } & =\text { Nilai WTP maksimum responden ke } \mathrm{i}\end{array}$

METODE PENELITIAN

\section{Survei Pengumpulan Data}

Pada penelitian ini ada dua macam data yang dikumpulkan data primer dan data sekunder. Data primer adalah data pokok yang didapatkan langsung di lokasi survei berupa waktu durasi parkir kendaraan di lokasi, jenis dan plat nomor kendaraan, serta ukuran dimensi parkir. Data sekunder didapatkan dari data yang sudah ada dan wawancara dengan pihak terkait, berupa denah lokasi parkir, fakta lapangan, serta informasi pendukung lain.

\section{Lokasi Penelitian}

Penelitian dilaksanakan pada daerah-daerah yang dilewati angkutan bus BST koridor 2. Dengan arah menuju Timut dengan rute Terminal Kartasura - Pabelan - Jl. Brigjen Slamet Riyadi - Jl. Dr. Cipto Mangunkusumo - Jl. Yosodipuro - Jl. Gajah Mada - Jl. Monginsidi - Jl. Kol. Sutarto - Jl. Ir. Sutami - Palur, yang ditunjukan pada Gambar 1. Sedangkan arah menuju Barat dengan rute Palur - Jl. Ir. Sutami - Jl. Kol. Sutarto - Jl. Monginsidi Jl. Gajah Mada - Jl. Yosodipuro - Jl. Dr. Moewardi - Jl. Brigjen Slamet Riyadi - Pabelan - Terminal Kartasura, yang ditunjukkna pada Gambar 2. berikut.

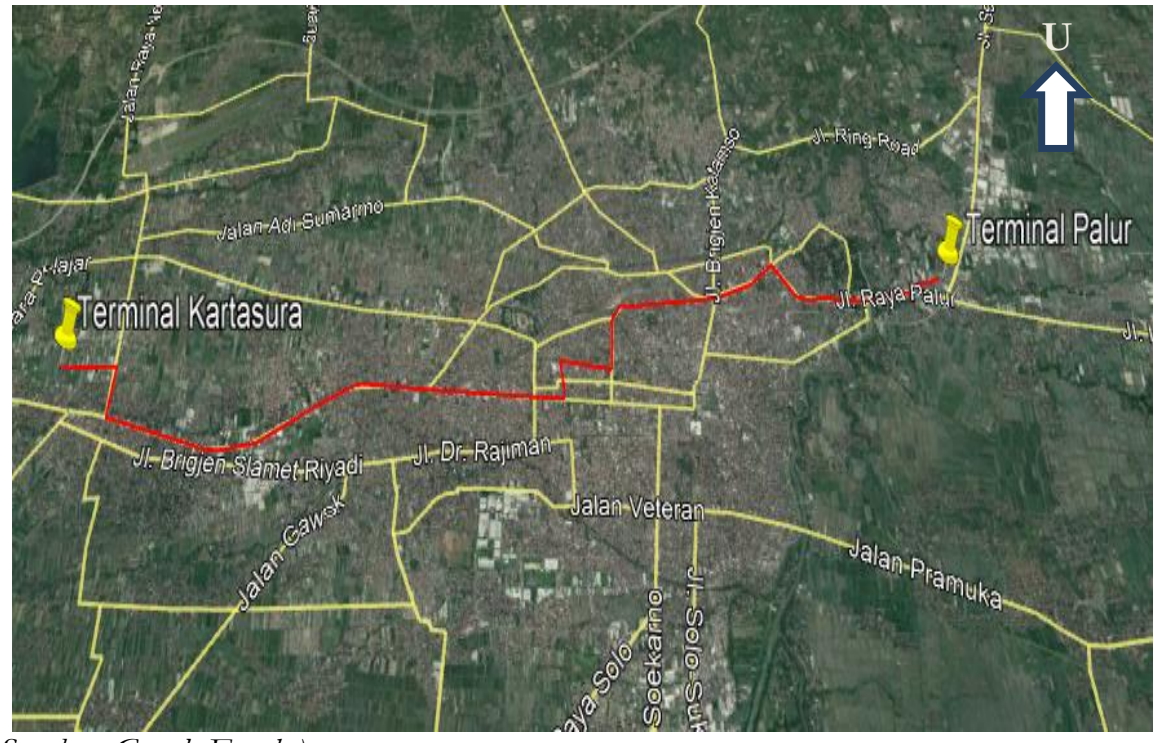

(Sumber: Google Earth)

Gambar 1. Lokasi Penelitian

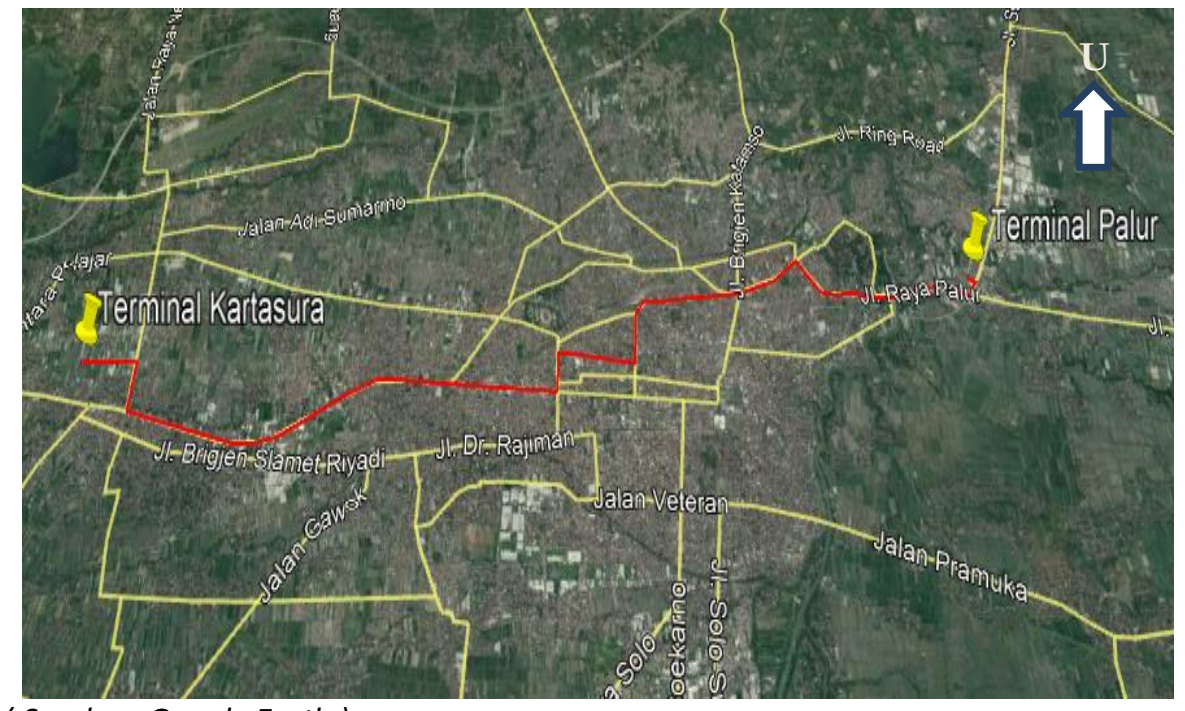

(Sumber: Google Earth)

Gambar 2. Lokasi Penelitian

\section{Waktu Penelitian}

Pengambilan data survey ini dilakukan pada hari toko buka (Senin- Minggu) pukul 09.00-22.00 WIB 


\title{
Prosedur Penelitian
}

Survei pendahuluan merupakan survei skala kecil tetapi sangat penting agar survei sesungguhnya dapat berjalan dengan lancar, efektif, dan efisien. Survei pendahuluan ini meliputi:

1. Perhitungan jumlah populasi

Perhitungan jumlah populasi dilakukan dengan menghitung seluruh jumlah pegawai dan pengunjung yang berada pada masing-masing pertokoan di dalam koridor.

2. Penentuan jumlah sampel

Penentuan jumlah sampel dilakukan setelah mendapatkan jumlah populasi. Jumlah populasi yang teramat banyak akan memakan waktu yang sangat lama untuk disurvei, oleh karena itu perlu dilakukan sampling.

3. Penentuan waktu survei

Pelaksanaan survei dilaksanakan pada jam kerja dan istirahat toko.

4. Penentuan jumlah surveyor

Penentuan jumlah surveyor sangat penting agar pelaksanaan survei dapat efisien dan efektif.

5. Pengecekan form survei

Pengecekan form survei bertujuan agar pada saat survei utama surveyor tidak mengalami kesulitan dalam mengisi formulir survei.

Pengambilan sampel merupakan upaya untuk memperoleh keterangan mengenai populasi dengan mengamati hanya sebagian dari populasi tersebut. Pengambilan sampel dilakukan karena sering tidak dimungkinkan untuk mengamati seluruh anggota populasi tersebut. Sampel yang telah dipilih diharapkan dapat mewakili populasi tersebut.

Supaya hasil penelitian yang dilakukan terhadap sampel dapat mewakili karakteristik populasi, maka cara penarikan sampel dilakukan secara seksama yang dikenal dengan nama teknik sampling atau teknik pengambilan sampling. Menentukan ukuran sampel menurut Slovin:

$n=\frac{N}{1+N e^{2}}$

Keterangan:

$\mathrm{n}=$ Ukuran sampel

$\mathrm{N}=$ Ukuran populasi

$\mathrm{E}=$ Persen kelonggaran ketidaktelitian karena kesalahan pengambilan sampel yang masih dapat ditolelir sampai $10 \%$.

\section{ANALISIS DATA DAN PEMBAHASAN}

\section{Analisis Data Responden}

Analisis karakteristik responden dilakukan dengan memberikan kuisioner kepada 404 responden pegawai dan pengunjung pertokoan. Kuisioner yang telah diisi kemudian dianalisis untuk mengidentifiaksi karakteristik responden.

Berdasarkan kuisioner yang telah dibagikan kepada responden didapat data jenis kelamin yang disajikan dalam bentuk diagram Gambar 1.

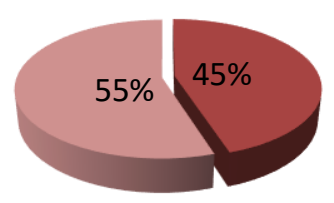

\author{
- Laki-laki \\ Perempuan
}

Sumber: Hasil Analisis

Gambar 1. Persentase Jenis Kelamin Responden

Kepopuleran BST bagi responden dapat mempermudah perpindahan dari kendaraan pribadi ke BST. Kepopuleran BST di kalangan responden dapat dilihat dari diagram Gambar 2. 


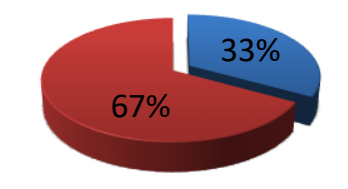

๑pernah

Delum

Sumber: Hasil Analisis

Gambar 2. Persentase Pernah atau Tidak Menggunakan BST

Berdasarkan tingkat pendidikan terakhir responden yang telah dibagikan ke responden dapat disajikan dalam diagram Gambar 3.
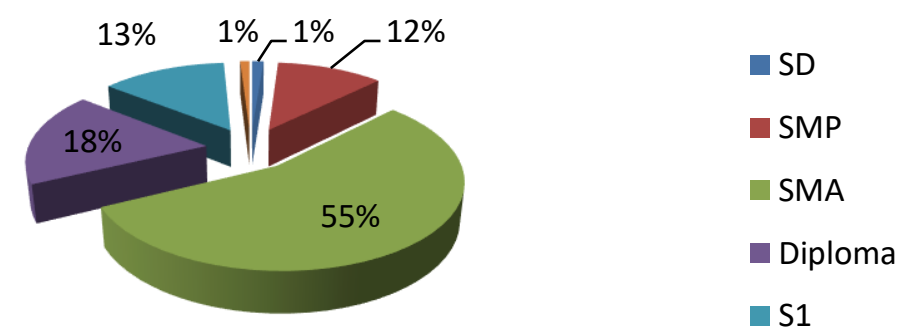

Sumber: Hasil Analisis

Gambar 3. Persentase Tingkat Pendidikan Terakhir

\section{Analisis Data Responden}

Analisis potensi demand merupakan analisis untuk mengetahui jumlah demand yang memiliki ketertarikan untuk menggunakan BST. Gambaran mengenai rasio responden yang termasuk potensi demand ditunjukkan pada Gambar 4.

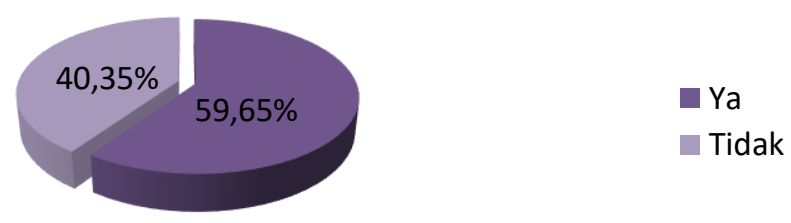

Sumber: Hasil Analisis

Gambar 4. Persentase Potensi Demand

Dari Gambar 4. menunjukkan bahwa sebanyak 40,35\% responden tidak bersedia menggunakan BST koridor 2 dan sebanyak 59,65\% responden bersedia menggunakan BST koridor 2. Data yang akan digumakan untuk analisis adalah data dari 59,65\% responden atau sebesar 241 responden. Orang-orang inilah yang disebut sebagai potensi demand.

Potensi demand didapat dari :

Total potensi demand $=\%$ potensi demand $\mathrm{x}$ populasi awal

$\frac{59,65}{100} \times 17961=10.714,4 \approx 10.714$ orang

Dari perhitungan di atas maka total potensi penambahan demand BST koridor 2 pada fungsi guna lahan pertokoan adalah 10.714 orang.

Nilai Tarif Berdasarkan ATP dan WTP 
Berikut gambar 5 merupakan gambar perbandingan tarif berlaku dengan nilai tarif ATP dan WTP kategori umum .

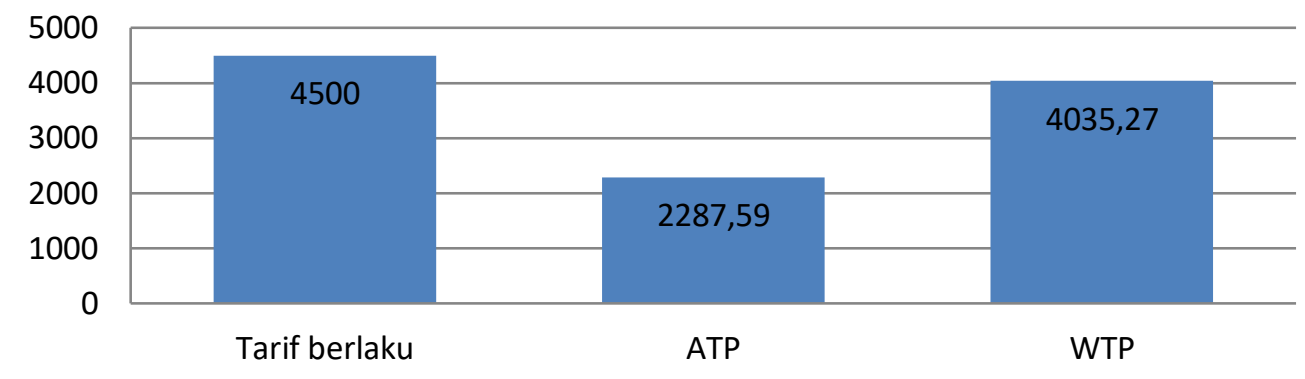

Sumber: Hasil Analisis

Gambar 5. Perbandingan Tarif Berlaku dengan nilai ATP dan WTP Kategori Umum

Berikut gambar 6 merupakan gambar perbandingan tarif berlaku dengan nilai tarif ATP dan WTP kategori pegawai .

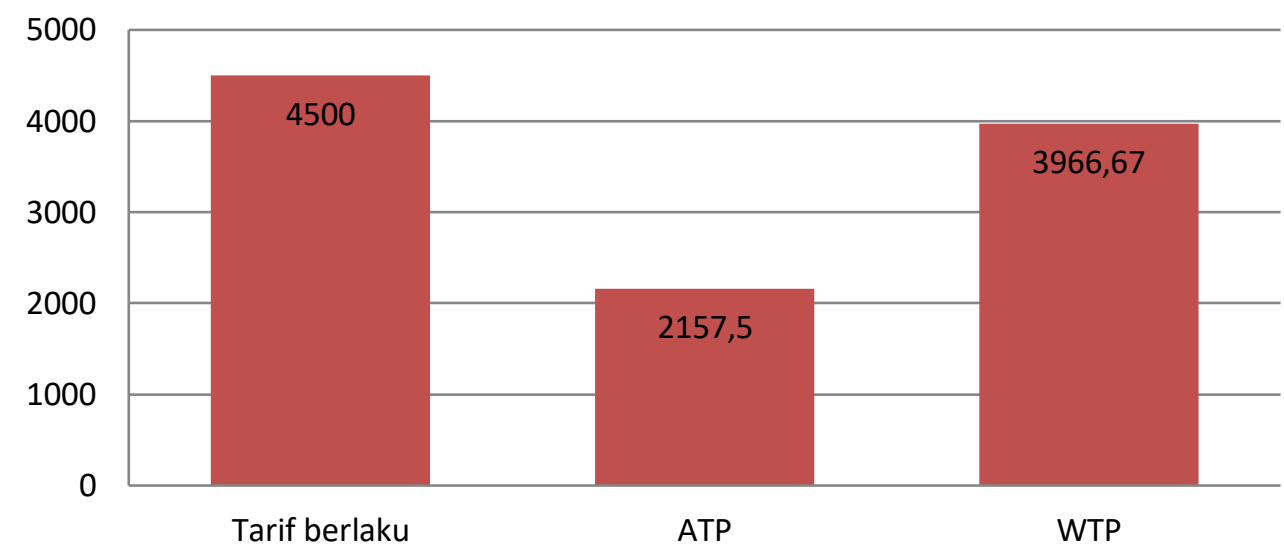

Sumber: Hasil Analisis

Gambar 6. Perbandingan Tarif Berlaku dengan nilai ATP dan WTP Kategori Pegawai

Berikut gambar 7 merupakan gambar perbandingan tarif berlaku dengan nilai tarif ATP dan WTP kategori pengunjung .

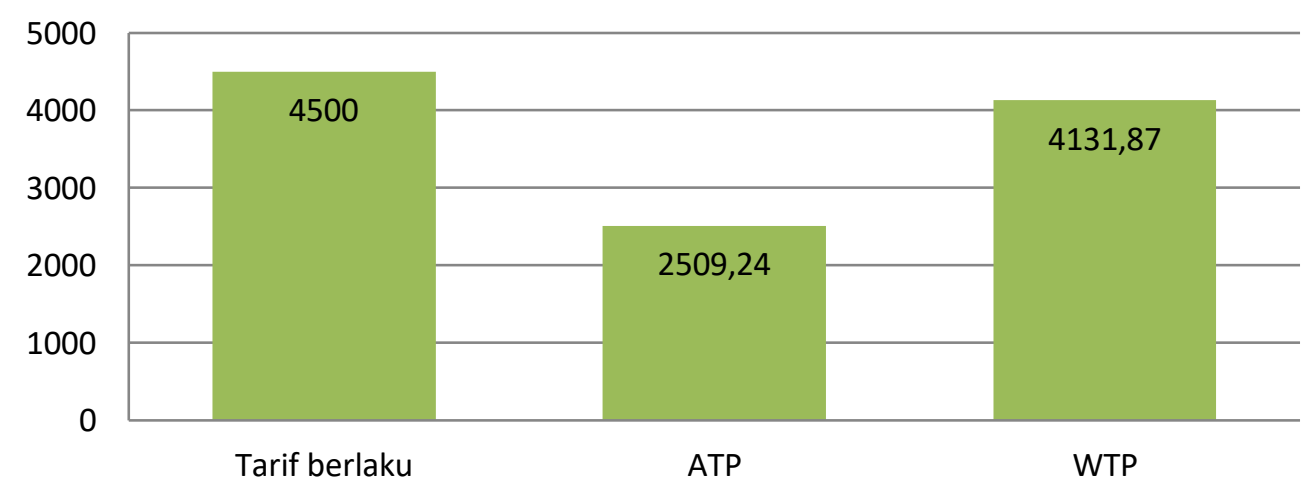

Sumber: Hasil Analisis

Gambar 7. Perbandingan Tarif Berlaku dengan nilai ATP dan WTP Kategori Pengunjung

\section{Pembahasan}

Analisis perhitungan yang sudah dilakukan jumlah potensi demand BST koridor 2 dari fungsi tata guna lahan pertokoan sebesar 59,65\% atau sebanyak 10.714 orang. Sebagian responden yang merupakan potensi 
penambahan demand tersebut mau beralih menggunakan BST koridor 2 setelah beberapa keluhan diperbaiki, diantaranya :

1. Jadwal bus yang tidak pasti

2. Interval waktu menunggu bus yang masih lama

3. Halte yang kurang nyaman

4. Kurangnya penjaga di setiap halte

Selain itu terdapat 40,35\% responden yang tidak menunjukkan ketertarikan menggunakan BST koridor 2. Sebagian besar responden lebih memilih menggunakan transportasi pribadi seperti motor maupun mobil. Serta responden memilih naik ojek online yang semakin marak, Responden menilai ojek online lebih praktis dan efisien untuk menunjang kebutuhan tranportasi mereka.

semua kategori nilai kemampuan membayar (ATP) lebih rendah daripada nilai kesediaan membayar (WTP) respoden dan nilai tersebut masih di bawah nilai tarif yang berlaku saat ini. Rendahnya kemampuan membayar dan kesediaan membayar tersebut dikarenakan penghasilan responden yang masih tergolong rendah,sebagian besar pegawai toko berpenghasilan sesuai dengan UMR Kota Surakarta dan persentase penghasilan untuk biaya transportasi juga tergolong sedikit.

Kondisi ini menggabarkan kemampuan pengguna untuk membayar (ATP) lebih kecil daripada kesediaan untuk membayar (WTP). Hal ini dapat terjadi karena pengguna memiliki utilitas atau penggunaan yang tinggi akan tetapi hanya memiliki pengahasilan yang rendah sehingga kesediaan pengguna untuk membayar tersebut relatif dipengaruhi oleh utilitas. Kebijakan dalam menentukan tarif sebaiknya melihat dari nilai ATP di mana nilai tarif yang berlaku tidak dianjurkan melebihi nilai ATP yang ada. Oleh karena itu campur tangan pemerintah baik dalam bentuk subsidi maupun dukungan lainnya sangat dibutuhkan agar nilai tarif yang berlaku sama dengan nilai ATP.

\section{SIMPULAN}

Berdasarakan hasil analisis yang sudah dilakukan, maka diperoleh kesimpulan sebagai berikut :

a. Potensi demand BST koridor 2 pada fungsi guna lahan pertokoan adalah 10.714 orang atau $60,35 \%$ dari total 17.961 sampel populasi.

b. Nilai Ability to Pay (ATP) potensi demand pada kategori umum sebesar Rp 2.287,59 dan Willingness to Pay (WTP) sebesar Rp 4.035,27. Untuk kategori pegawai nilai ATP sebesar Rp 2.157,50 dan nilai WTP sebesar Rp 3.966,67. Untuk kategori pengunjung nilai ATP sebesar Rp 2.509,24 dan nilai WTP sebesar Rp 4.131,87. Berdasar kan nilai tersebut bahwa nilai WTP lebih tinggi daripada nilai ATP dan masih lebih rendah daripada tarih yang berlaku saat ini yaitu Rp 4.500,00.

\section{SARAN}

Berdasarkan analisis yang sudah dilakukan, beberapa saran yang mungkin dapat bermanfaat antara lain :

a. Perlu ditambah peningkatan kualitas guna menambah ketertarikan menggunakan BST, yaitu : penambahan petugas pada halte BST, peningkatan kualitas halte, penambahan jumlah armada bus.

b. Pemerintah perlu menentukan tarif baru yang sesuai berdasarkan nilai ATP dan WTP sehingga tariff bias lebih terjangkau.

c. Waktu kedatangan bus yang singkat dan bebas biaya perpindahan koridor dapat menarik minat masyarakat dalam menggunakan BST.

\section{DAFTAR PUSTAKA}

Anonim. 2018. Definifi Toko. Kamus Besar Bahasa Indonesia. http://kbbi.web.id/toko. (17 Februari 2018)

Alviano, Reza. 2015. Analisis Tarif dan Penambahan Demand Batik Solo Trans Koridor 1 Khusus Mahasiswa UNS Menggunakan Metode Ability to Pay (ATP), Willingness to Pay (WTP), dan Biaya Operasional Kendaraan (BOK). Skripsi. Jurusan Teknik Sipil Fakultas Teknik UNS Surakarta.

Black. 1995. Urban Mass Transportation Planning. United States: McGraw-Hill International Editions. University of Kansas.

Button, K.J. 1982. Transport Economics. London, England: Heineman. 
Departemen Perhubungan Umum 1993. Peraturan Pemerintah Republik Indonesia Nomor 41 Tahun 1993 tentang Angkutan Jalan. Jakarta

Hobbs, F.D. 1979. Perencanaan dan Teknik Lalu Lintas Edisi Pertama. Yogyakarta: UGM Press.

Khisty, K dan Lall, B.K. 2003.Dasar - dasar Rekayasa Transportasi Jilid I. Jakarta: Penerbit Erlangga.

Krisnanto, Albertus Ryan. 2014. Evaluasi Tarif Berdasarkan Biaya Operasional Kendaraan (BOK), Ability to Pay (ATP), Willingness to Pay (WTP), dan Analisis Breakeven Point (BEP) Bus Batik Solo Trans(Studi Kasus: Koridor 2). Skripsi. Jurusan Teknik Sipil Fakultas Teknik UNS. Surakarta.

Minderhoud, M. M dan Zuylen, H. J Van. 2005. Willingness to Pay (WTP) for Personal Rapid Transit in The City of Amela. Jurnal Transport and Planning Delft University of Technology. Delf : Delf University of Technology.

Morlok, E.K. 1998. Pengantar Teknik dan Perencanaan Transportasi. Jakarta:

Neumann, Marika. 2006. Fare Planning for Public Transport. Konrad - Zuse - Zentrum fur Informations Technik Berlin. Germany.

Saputra, Aditya Krisnanda Bagus. 2015. Analisis Tarif Batik Solo Trans Koridor 2 berdasarkan Estimasi Penambahan Demand Mahasiswa Universitas Sebelas Maret Menggunakan Metode Ability to Pay (ATP), Willingness to Pay (WTP), dan Biaya Operasional Kendaraan (BOK). Skripsi. Jurusan Teknik Sipil Fakultas Teknik UNS Surakarta.

Sinulingga, Budi. D. 1999. Pembangunan Kota Tinjauan Regional dan Lokal. Jakarta: Pustaka Sinar Harapan.

Susanto, Angga Dicky. 2016. Analisis Potensi Demand, Ability to Pay (ATP) dan Willingness to Pay (WTP) BST Koridor 1 Dengan Adanya Sistem Contra Flow Di Jalan Bringjen Slamet Riyadi Pada Pertokoan. Skripsi. Jurusan Teknik Sipil Teknik UNS Surakarta.

Tamin. O. Z. 1999. Studi Evaluasi Tarif Angkutan Umum dan Analisis Ability to Pay (ATP) dan Willingness to Pay (WTP) di DKI Jakarta. Jakarta: Yayasan Lembaga Konsumen Indonesia (YLKI).

Yuniarti, Taty. 2011. Analisis Tarif Angkutan Umum Berdasarkan Biaya Operasional Kendaraan, Ability To Pay dan Wilingness To Pay (Studi Kasus PO. ATMO Trayek Palur-Kartasura di Surakarta). Skripsi.Jurusan Teknik Sipil Fakultas Teknik UNS. Surakarta. 